\title{
EHF enhances malignancy by modulating AKT and MAPK/ERK signaling in non-small cell lung cancer cells
}

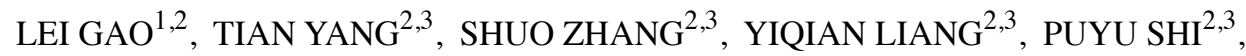 \\ HUI REN ${ }^{2,3}$, PENG HOU ${ }^{4}$ and MINGWEI $\mathrm{CHEN}^{2,3}$ \\ ${ }^{1}$ Department of Endocrinology, The Second Affiliated Hospital of Xi'an Jiaotong University, Xi'an, Shaanxi 710004; \\ ${ }^{2}$ Shanxi Provincial Research Center for The Project of Prevention and Treatment of Respiratory Diseases; \\ Departments of ${ }^{3}$ Respiratory and Critical Care Medicine and ${ }^{4}$ Endocrinology, \\ The First Affiliated Hospital of Xi'an Jiaotong University, Xi'an, Shaanxi 710061, P.R. China
}

Received October 16, 2019; Accepted September 18, 2020

DOI: 10.3892/or.2021.8053

\begin{abstract}
Overexpression of ETS-homologous factor (EHF) in non-small cell lung cancer (NSCLC) is associated with poor patient prognosis. To explore the mechanism of the effect of EHF in NSCLC, EHF expression was examined in NSCLC and its role in cell proliferation, invasion, cell cycle, and apoptosis of NSCLC cells was evaluated by overexpressing EHF and/or knocking down EHF expression in NSCLC cells in vitro and in cancer cell grafted mice in vivo. The results revealed that the knockdown of EHF expression in NSCLC with siRNA significantly inhibited cell proliferation and invasion, arrested the cell cycle at the $G_{0} / G_{1}$ phase, and induced apoptosis, whereas overexpression of EHF in NSCLC promoted cell proliferation, tumor growth, and cancer cell migration in vitro. The in vivo experiments demonstrated that siRNA-mediated downregulation of EHF expression in NSCLC cells significantly suppressed tumor growth in xenografted nude mice as compared to cancer progression in the mice grafted with NSCLC cells transfected
\end{abstract}

Correspondence to: Dr Mingwei Chen, Department of Respiratory and Critical Care Medicine, The First Affiliated Hospital of Xi'an Jiaotong University, 277 West Yanta Road, Xi'an, Shaanxi 710061, P.R. China

E-mail: chenmingwei@mail.xjtu.edu.cn

Dr Peng Hou, Department of Endocrinology, The First Affiliated Hospital of Xi'an Jiaotong University, 277 West Yanta Road, Xi'an, Shaanxi 710061, P.R. China

E-mail:phou@xjtu.edu.cn

Abbreviations: NSCLC, non-small cell lung cancer; ETS, E26 transformation-specific; PEA3, polyoma enhancer activator 3; ESE-1, epithelial-specific expression-1; EHF, ETS-homologous factor; qPCR, quantitative PCR; FBS, fetal bovine serum; PI, propidium iodide; ChIP, chromatin immunoprecipitation; SD, standard deviation; STAT, signal transducer and activator of transcription

Key words: non-small cell lung cancer, gene regulation, protein/DNA interaction, tyrosine kinase receptor, protein phosphorylation with non-specific control siRNA. The biochemical analyses revealed that EHF promoted NSCLC growth by regulating the transcription of Erb-B2 receptor tyrosine kinase 2/3 (ERBB2, ERBB3) and mesenchymal-epithelial transition (MET) factor tyrosine kinase receptors and modulating the AKT and ERK signaling pathways in the NSCLC cells. The present findings indicated that EHF could be used as a prognostic marker for NSCLC, and tyrosine kinase receptors of ERBB2, ERBB3 and MET could be drug targets for NSCLC treatment.

\section{Introduction}

Non-small cell lung cancer (NSCLC), the most common lung cancer, is one of the leading causes of cancer-related deaths in patients of developed countries $(1,2)$. In general, the long-term survival of patients with NSCLC is markedly poor because the cancer cells are resistant to chemotherapy and radiotherapy (3). The molecular mechanisms of cancer cell resistance to anticancer drugs and the pathogenesis of NSCLC progression remain unclear. Therefore, the elucidation of lung cancer pathogenesis, the study of molecular mechanisms of NSCLC progression, and the identification of specific biomarkers and therapeutic targets are required for development of improved strategies for NSCLC diagnosis, prognosis and treatment.

E26 transformation-specific (ETS) transcription factors are known to play key roles in cell differentiation, tissue development and oncogenesis (4-6). Little is known about how these transcription factors govern the proliferation, migration, and apoptosis of lung cancer cells. It has been revealed that ETS factors regulate the expression of their target genes by binding to ETS response elements in the promoters, and promote cancer development in part by regulating expression of matrix metalloproteinases, thus influencing normal tissue growth and promoting cell invasion, metastasis, and angiogenesis in cancers (7). Some of the ETS family members including polyoma enhancer activator 3 (PEA3) and epithelial-specific expression-1 (ESE-1) have been implicated in the regulation of HER2 oncogene transcription and promotion of breast cancer growth $(8,9)$. Expression of ETS-homologous factor (EHF), also known as ESE-1, is mainly restricted to the glandular organs (10). Loss of EHF expression has been revealed in 
several epithelial carcinomas, including bladder, oral squamous, and breast ductal carcinomas (11), and a downregulation of EHF expression is associated with prostate cancers $(12,13)$. While overexpression of EHF in breast cancers is not associated with poor prognosis of progression-free survival, the expression level of EHF has been revealed to be significantly higher in primary lung cancer tissues compared with adjacent non-tumor tissues of the same patients $(14,15)$. Data obtained from public datasets indicate that a high level of EHF expression is associated with poor prognosis of patients with NSCLC, and that loss of EHF expression impairs the invasion and the metastasis of lung cancer cells $(16,17)$. These studies suggest that EHF may have distinct tissue-specific functions in various cancers (12-17). EHF has been revealed to promote lung cancer cell progression but inhibit epithelial carcinomas and prostate cancer growth. The different signaling pathways of EHF in lung cancer cells vs. epithelial carcinomas remain unknown.

In the present study, the expression level of EHF in primary NSCLC was compared with that found in adjacent non-tumor lung tissue and the role of EHF in NSCLC progression in vitro and in vivo was investigated to explore the mechanism of EHF action in lung cancer cells.

\section{Material and methods}

Human lung cancer cell lines and antibodies. Cell lines A549, LTEP-s, and 95D were obtained from the Chinese Academy of Sciences Cell Bank of Type Culture Collection. Anti-EHF (product code ab220113) and anti-pan-ERK1/2 (product code ab17942) antibodies were purchased from Abcam. Anti-phospho-AKT ${ }^{\mathrm{Ser} 473}$ (cat. no. BS4006), anti-total-AKT (cat. no. BS1810), and anti-phospho-ERK1/2 (cat. no. BS4621) antibodies were obtained from Bioworld Technology, Inc. Anti-Ki67 antibody (cat. no. 550609) was a product of BD Biosciences. Anti-GAPDH antibody (cat. no. AM8539b) was obtained from Abcepta, Inc. The sources and dilutions of the primary antibodies used for western blot analysis are listed in Table SI.

Human lung cancer and control tissues. Twenty-one NSCLC and adjacent non-tumor tissues were surgically collected from patients who had not undergone chemotherapy or radiotherapy before the surgery at the First Affiliated Hospital of Xi'an Jiaotong University, Xi'an, China from October 2013 to April 2014. The detailed background data of the studied subjects including sex, age medical history, histologic grade, tumor stage location were listed in a previous study (18). None of the patients enrolled received local or systemic treatment before operation and all of them provided informed written consent for participation in the present study. The study was approved by the Institutional Review Board and Human Ethics Committee of the First Affiliated Hospital of Xi'an Jiaotong University, and written informed consent was obtained from each patient.

Bioinformatics. Gene expression data (RNA-seq) from 513 lung adenocarcinomas and 58 matched normal tissues, and from 509 patients with lung squamous cell carcinoma including 44 paired tumor and normal tissues were downloaded on July 15, 2014 from The Cancer Genome Atlas (TCGA; http://cancergenome.nih.gov/). The median of gene expression was used for the Kaplan-Meier plot to analyze the association of marker gene expression with the survival of patients. The hazard ratio, 95\% confidence intervals, and log rank P-value were calculated for each gene automatically using web-based software tools at www.kmplot.com/lung.

$R N A$ extraction and reverse transcription-quantitative polymerase chain reaction ( $R T-q P C R)$. Total RNA was extracted with TRIzol ${ }^{\circledR}$ reagent (Takara Bio, Inc.) from clinical samples, cancer cell lines and grafted tumors. An aliquot of total RNA $(1 \mu \mathrm{g})$ was reverse transcribed into cDNA in $20 \mu \mathrm{l}$ volume of reaction by random primers. Quantitative PCR (qPCR) contained $0.5 \mu 1$ template cDNA, 1X SYBR ${ }^{\circledR}$ Premix Ex Taq ${ }^{\mathrm{TM}}$ with a qPCR kit from Takara Bio, Inc. (Takara Bio, Inc.), and $100 \mathrm{nM}$ of specific forward and reverse primers in $25 \mu \mathrm{l}$ volume of reaction. Primers used for real-time PCR are listed in Table I. The PCR thermocycling conditions were as follows: $95^{\circ} \mathrm{C}$ for $5 \mathrm{~min}, 1$ cycle, followed by 40 cycles at $95^{\circ} \mathrm{C}$ for $45 \mathrm{sec}, 59^{\circ} \mathrm{C}$ for $45 \mathrm{sec}$ and $72^{\circ} \mathrm{C}$ for $45 \mathrm{sec}$. The final PCR products were extended for $5 \mathrm{~min}$. Housekeeping gene, GAPDH was used as a reference. The $2^{-\Delta \Delta \mathrm{Cq}}$ method was used to analyze the data (19).

Gene knockdown, transfection and plasmid construction. Cancer cells $\left(1 \times 10^{5}\right)$ were cultured in 6-well plates in OPTI-MEM medium (Invitrogen; Thermo Fisher Scientific, Inc.) supplemented with $10 \%$ fetal bovine serum (FBS) (Hyclone; Cytiva), $100 \mu \mathrm{g} / \mathrm{ml}$ penicillin, $100 \mathrm{units} / \mathrm{ml}$ streptomycin (Hyclone; Cytiva) at $37^{\circ} \mathrm{C}$ in a humidified incubator containing $5 \% \mathrm{CO}_{2}$ for $18 \mathrm{~h}$. The following day, the cells were transfected with $400 \mu \mathrm{l}$ of antibiotic-free and serum-free medium OPTI-MEM containing $2 \mu \mathrm{g}$ of plasmid DNA and $4 \mu \mathrm{l}$ of Lipofectamine 2000 (Invitrogen; Thermo Fisher Scientific, Inc.) according to manufacturer's instructions. Six hours later, the medium was removed, and fresh growth medium was added. The cells were cultured at $37^{\circ} \mathrm{C}$ for another $48 \mathrm{~h}$ prior to harvesting for total cellular protein or RNA extraction. Gene expression in cancer cells was knocked down by transfection with $50 \mathrm{nM}$ small interfering (si)RNAs using Lipofectamine $^{\circledR} 2000$ (Invitrogen; Thermo Fisher Scientific, Inc.). siRNAs against EHF (si-EHF-309 and si-EHF-979) and negative control siRNA (si-NC) were obtained from Shanghai GenePharma Co., Ltd. Full-length EHF cDNA was amplified by PCR and cloned into the pcDNA3.1 plasmid (Invitrogen; Thermo Fisher Scientific, Inc.). The promoters of Erb-B2 receptor tyrosinekinase 2/3 (ERBB2 and ERBB3), as well as MET genes were generated by PCR and inserted into the pGL3-basic plasmid (Promega Corporation). The sequences were verified by DNA sequencing. Primers used for generation of reporter constructs and ChIP assays are listed in Tables II and III. The sequences of siRNAs used are listed in Table IV.

Cytotoxicity and colony formation assays. The 3-(4,5-dimethylthiazol-2-yl)-2,5-diphenyltetrazolium bromide (MTT) assay from Sigma-Aldrich; Merck KGaA was used to determine cell viability/cytotoxicity as reported (20,21). Briefly, $20 \mu \mathrm{l}$ MTT solution $(5 \mathrm{~g} / \mathrm{l})$ was added to a well of a 96 -well plate and the NSCLC cells were cultured at $37^{\circ} \mathrm{C}$ for an additional $4 \mathrm{~h}$. After removal of the supernatant, $150 \mu \mathrm{l}$ dimethyl sulfoxide was added to each well and the plates were oscillated for $15 \mathrm{~min}$. Absorbance of insoluble formazan, which has a purple color was measured at a test wavelength of $570 \mathrm{~nm}$ and a reference 
Table I. Primer sequences used for RT-qPCR.

\begin{tabular}{lll}
\hline Gene & \multicolumn{1}{c}{ Forward primer $\left(5^{\prime}-3^{\prime}\right)$} & \multicolumn{1}{c}{ Reverse primer $\left(5^{\prime}-3^{\prime}\right)$} \\
\hline$E H F$ & TGATTCTGGAAGGAGGTGGT & ATGTCGAACTCTTGGAAAGGG \\
$E G F R$ & GGGCTCTGGAGGAAAAGAAA & AAATTCCCAAGGACCACCTC \\
$E R B B 2$ & ATCAACTGCACCCACTCCTG & TGATGAGGATCCCAAAGACCAC \\
$E R B B 3$ & AGTCATGAGGGCGAACGAC & TCACACTCAGGCCATTCAGA \\
$M E T$ & ACGGGATCTGAGACTTCCAA & TTATTCTCCGTTCCTGCACA \\
$18 S$ & CTCCAGCATTTTTACGGACC & GCTGCAAAGCTGTGGTAAACT \\
$G A P D H$ & CGCCGCTAGAGGTGAAATTC & CTTCGCTCTGGTCCGTCTT \\
\hline
\end{tabular}

RT-qPCR, reverse transcription-quantitative polymerase chain reaction; EHF, ETS-homologous factor.

Table II. Primer sequences for ChIP assays.

\begin{tabular}{lclll}
\hline Genes & Sets & \multicolumn{1}{c}{ Forward primer (5'-3') } & \multicolumn{1}{c}{$\begin{array}{c}\text { Product } \\
\text { length (bp) }\end{array}$} \\
\hline ERBB2 & P1:-604- -484 & TCCTTTCGATGTGACTGTCTCC & TGTGTTTACCTTGTGGCTTCC \\
& P2:-274- -155 & TGCATTTAGGGATTCTCCGA & ACTCCCAGCTTCACTTTCTC & 121 \\
& P3: $-147--37$ & CCCAGACTTGTTGGAATGCAG & ATTCTTATACTTCCTCAAGCAGCC & 111 \\
ERBB3 & P4:-203- -81 & TTCGAGTCTGGGAGAAACTGAG & TAGCCGGTTGGTTCACTTGG & 123 \\
& P5:-77- +43 & GAGTTGAGTGATTTGGTTAATGGG & GAGGTCGAGATTCCGAAAGC & 120 \\
& P6:-258- -141 & GACTCGGTCCCGCTTATCTC & GCCCACGACAAGGTGAAAC & CCAGGAACCAGTGGAGAAGT \\
& P7:+249- +387 & AGCGCTTTGTGAGCAGATG & 139 \\
\hline
\end{tabular}

ChIP, chromatin immunoprecipitation.

Table III. Primer sequences for generation of luciferase reporter constructs.

\begin{tabular}{|c|c|c|c|c|}
\hline Plasmids & Sets & Forward primer $\left(5^{\prime}-3^{\prime}\right)$ & Reverse primer $\left(5^{\prime}-3^{\prime}\right)$ & Restriction sites \\
\hline pcDNA $^{\mathrm{TM}} 3.1 /$ myc-His(-)A-EHF & & $\begin{array}{l}\text { CCGCTCGAGGCCACCA } \\
\text { TGATTCTGGAAGGAGGT } \\
\text { GGTG }\end{array}$ & $\begin{array}{l}\text { CCСAAGCTTGTTT } \\
\text { TCATTTTCTCTCCAT } \\
\text { CСТCG }\end{array}$ & XhoI and HindIII \\
\hline pGL3-ERBB2-Luc & $-607-+11$ & $\begin{array}{l}\text { CGGGGTACCAAGTCCT } \\
\text { TTCGATGTGACTGTC }\end{array}$ & $\begin{array}{l}\text { CCGCTCGAGCTGG } \\
\text { TTTCTCCGGTCCCAAT }\end{array}$ & $K p n I$ and $X h o I$ \\
\hline pGL3-ERBB3-Luc & $-997-+440$ & $\begin{array}{l}\text { CGGGGTACCAGGTTG } \\
\text { CATATCAATAGGGAGC }\end{array}$ & $\begin{array}{l}\text { CCCAAGCTTGACTCC } \\
\text { GCAGAGGGTGAAG }\end{array}$ & KpnI and HindIII \\
\hline pGL3-MET-Luc & $-223-+60$ & $\begin{array}{l}\text { CGAGCTCCAGACTGC } \\
\text { CTGAGCTGGGGGA }\end{array}$ & $\begin{array}{l}\text { CCCAAGCTTGCGACC } \\
\text { AGACTGAGGCGCTC }\end{array}$ & SacI and HindIII \\
\hline
\end{tabular}

wavelength of $670 \mathrm{~nm}$ by a spectrometer. For colony formation assays, 1,000 cells/well were seeded into 6-well plates, and the media were changed every 3 days. After 10-14 days of culture, cells were fixed with $100 \%$ methanol at room temperature for $20 \mathrm{~min}$, stained with $0.5 \%$ crystal violet at room temperature for $10 \mathrm{~min}$, and the colonies (>150 cells) were counted under a light microscope with a magnification of $\mathrm{x} 100$.

Migration and invasion assays. Cell migration and invasion assays were performed using Millicell ${ }^{\circledR}$ chambers $(8-\mu \mathrm{m}$ pore size; EMD Millipore). For cell invasion assays, chambers were coated with Matrigel ${ }^{\circledR}$ (4X dilution; $15 \mu \mathrm{l} /$ well; BD Biosciences). For cell invasion and migration, cells were transfected with siRNA for $48 \mathrm{~h}$ and then seeded in the upper chamber at a density of $1 \times 10^{5}$ cells $/ \mathrm{ml}$ in $200 \mu \mathrm{l}$ of medium containing $0.5 \%$ FBS. Medium containing $20 \%$ FBS was added to the lower chamber. After 24 or $48 \mathrm{~h}$ of incubation, non-invading cells in the upper chamber were removed, and invading cells were fixed in $100 \%$ methanol at room temperature for $20 \mathrm{~min}$ and stained with $0.5 \%$ crystal violet at room 
Table IV. siRNA sequences used in the present study.

siRNAs Sequences (5'-3')

\section{si-EHF-309 (Sense) \\ si-EHF-309 \\ (Antisense) \\ si-EHF-979 (Sense) \\ si-EHF-979}

(Antisense)

si-NC (Sense)

si-NC (Antisense)
GCCAGUGGCAUGAAAUUCATT UGAAUUUCAUGCCACUGGCTT

\section{CAGCCGAGCUAUGAGAUAUTT AUAUCUCAUAGCUCGGCUGTT}

\section{UUCUCCGAACGUGUCACGUTT ACGUGACACGUUCGGAGAATT}

siRNA, small interfering RNA; EHF, ETS-homologous factor; NC, negative control.

temperature for $10 \mathrm{~min}$. Images were captured randomly from 5 fields of each membrane. The number of invasive/migrated cells was counted and the average number of cells per light microscopic field with a magnification of $\mathrm{x} 200$ was presented.

Cell cycle and apoptosis assays. Lung cancer cells $\left(2 \times 10^{6}\right)$ were transfected with siRNA for $48 \mathrm{~h}$, and then synchronized by serum starvation for $16 \mathrm{~h}$. Cells were harvested at 24, 36 and $48 \mathrm{~h}$, respectively, and fixed in $70 \%$ ethanol on ice for $30 \mathrm{~min}$, followed by propidium iodide (PI) staining in a PBS buffer containing $50 \mu \mathrm{g} / \mathrm{ml}$ PI, $50 \mu \mathrm{g} / \mathrm{ml}$ RNase A, $0.1 \%$ Triton $^{\mathrm{TM}} \mathrm{X}-100$, and $0.1 \mathrm{mM}$ ethylenediaminetetraacetic acid. Stained cells were then examined by fluorescence-activated cell sorting (FACS) using a flow cytometer (FACSCalibur; BD Biosciences). The cell-cycle populations were determined by FlowJo 7.6 software analyses. For apoptosis assays, cells were harvested and stained in the dark with an Annexin V-FITC/PI solution (Roche Applied Science) at room temperature for $15 \mathrm{~min}$, followed by flow cytometric analyses. Thus, the early apoptotic cells are Annexin V-positive and PI-negative whereas the late apoptotic cells are Annexin V- and PI-positive.

Tumor xenografted mice. Ten four-week-old female BALB/c mice $(20 \mathrm{~g})$ were purchased from the Animal Experimental Center of the College of Medicine, Xi'an Jiaotong University. Mice were under the care of a qualified veterinarian at the approved animal facility of this institution under standard approved laboratory conditions with controlled illumination (14-h light and 10-h dark cycles) and temperature $\left(22^{\circ} \mathrm{C}\right)$ and unrestricted food and water. Ten mice were randomly divided into two groups $(\mathrm{N}=5)$ and anesthetized with $2.5 \%$ isoflurane prior to procedures. Depth of anesthesia was monitored by tracking respiration rate, and testing for a toe-pinch reflex every $15 \mathrm{~min}$. A total of $5 \times 10^{6}$ cancer cells was injected subcutaneously into the right dorsum of the mouse. Mice were monitored for discomfort and ease of movement every $12 \mathrm{~h}$ in the 2 days post-injection and frequently afterward. Discomfort was recognized as a reluctance to move, a hunched posture and poor grooming (a mottled face). To avoid mouse suffering, severely sick mice would be euthanized, however, in the present study, no sick mice were observed and euthanized. Tumor size was measured every 2 days, and the volume was calculated by length $\mathrm{x}$ width $2 / 2$. Mice were euthanized with a $30 \%$ flow rate of $\mathrm{CO}_{2}$ prior to cervical dislocation on day 21 after injection. Sacrifice was verified by lack of pulse and respiration over a period of at least $10 \mathrm{~min}$ followed by decapitation. The tumors were surgically excised, weighed, fixed in $10 \%$ formalin at $4^{\circ} \mathrm{C}$ for $72 \mathrm{~h}$, washed with $3 \mathrm{X}$ PBS, embedded in paraffin, and sectioned into $4-\mu \mathrm{m}$ slices. Ki67 immuno-staining was carried out with a primary antibody at $1: 100$ dilution at $4^{\circ} \mathrm{C}$ overnight, followed by incubation with biotin-labeled secondary antibody (cat no. SP-9002; ZSGB-BIO; OriGene Technologies, Inc.) at room temperature for $1.5 \mathrm{~h}$, washing 3 times, and another incubation with HRP-conjugated avidin working solution (cat. no. SP-9001; ZSGB-BIO; OriGene Technologies, Inc.) at room temperature for $20 \mathrm{~min}$. After washing 3 times with PBS, the cells were stained with DAB working solution (1:20 dilution) for $5 \mathrm{~min}$, followed by hematoxylin staining for $30 \mathrm{sec}$. The mean proportion of positive cells was calculated from 10 randomized microscopic fields at a magnification of x200. A Ki67-labeling index was calculated as the number of positive nuclei divided by the total number of nuclei. The experiments were approved by the Institutional Animal Care and Use Committee of Xi'an Jiaotong University.

Luciferase reporter and chromatin immunoprecipitation (ChIP) assays. A dual luciferase reporter assay system was used to measure the promoter activity according to manufacturer's instruction (Promega Corporation). The Renilla luciferase driven by TK minimal promoter was used as an internal control to normalize the transfection efficiency. Luciferase activity was measured $48 \mathrm{~h}$ post-transfection by using an EnSpire ${ }^{\circledR}$ multimode plate reader (Perkin Elmer, Inc.). ChIP assay was carried out according to the manufacturer's instructions (Pierce ${ }^{\mathrm{TM}}$ magnetic ChIP kit; Thermo Fisher Scientific, Inc. cat. no. 25157). Briefly, $2 \times 10^{6}$ cells were transfected with Myc-tag EHF expression construct and cross-linked in $1 \%$ formaldehyde at $37^{\circ} \mathrm{C}$ for $10 \mathrm{~min}$ and lysed in SDS lysis buffer (Pierce magnetic ChIP kit; Thermo Fisher Scientific, Inc.) supplemented with protease inhibitor cocktail (Sigma-Aldrich; Merck KGaA) for $10 \mathrm{~min}$ on ice. The lysate was sonicated and precleared with protein A agarose/salmon sperm DNA prior to immunoprecipitation with $1 \mu \mathrm{g}$ of anti-Myc Tag antibody (cat. no. 05-724; Clone 4A6; EMD Millipore) at $4^{\circ} \mathrm{C}$ overnight. Following wash and elution steps, cross-links were reversed at $65^{\circ} \mathrm{C}$ for $4 \mathrm{~h}$. The DNA in the immunoprecipitated samples was purified by proteinase $\mathrm{K}$ digestion followed by DNA purification. An aliquot of purified DNA was analyzed by quantitative PCR with specific primers.

Western blot analysis. The lung cancer cell lines and tumor tissues were homogenized and lysed with lysis buffer [20 mM Tris-HCl (pH 7.5), 150 mM NaCl, 1 mM EDTA, 1 mM EGTA, $1 \%$ NP-40, $1 \mathrm{mM}$ phenylmethylsulfonyl fluoride, $1 \mathrm{X}$ protease inhibitor cocktail and $1 \mathrm{X}$ phosphatase inhibitor cocktail] on ice for $20 \mathrm{~min}$, followed by centrifugation at $9,000 \mathrm{x} \mathrm{g}$ for $10 \mathrm{~min}$ at $4^{\circ} \mathrm{C}$. Total cellular protein was measured by bicinchoninic acid (BCA) assay. An aliquot of total cellular protein $(30 \mu \mathrm{g})$ was resolved on $8 \%$ SDS-polyacrylamide gel electrophoresis, transferred to membranes, blocked in $5 \%$ of fat free milk at room temperature for $4 \mathrm{~h}$, and immunoblotted with validated primary antibodies at 1:500-1,000 dilutions at $4^{\circ} \mathrm{C}$ overnight. Specific protein was detected using appropriate HRP-conjugated 
A

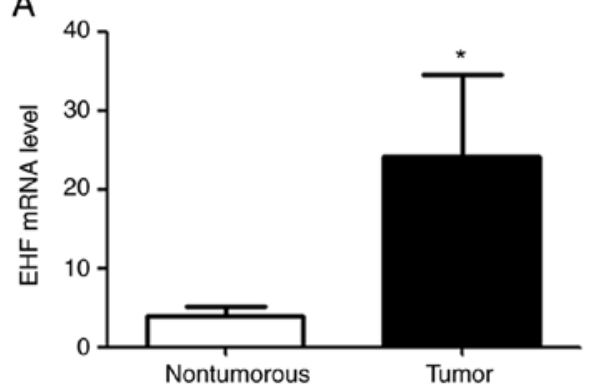

B-a

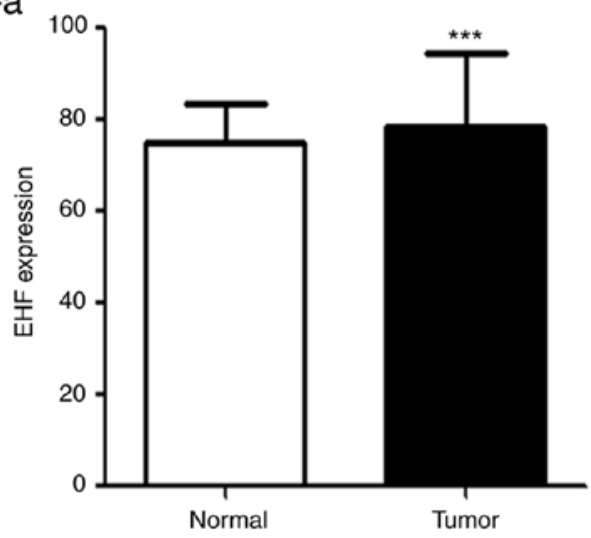

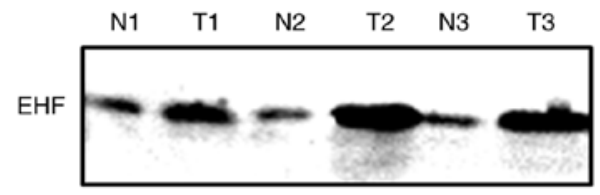

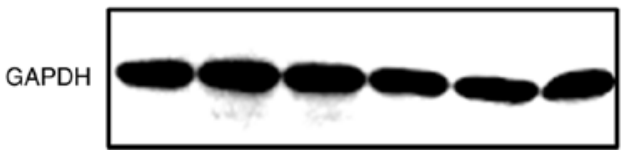

B-b

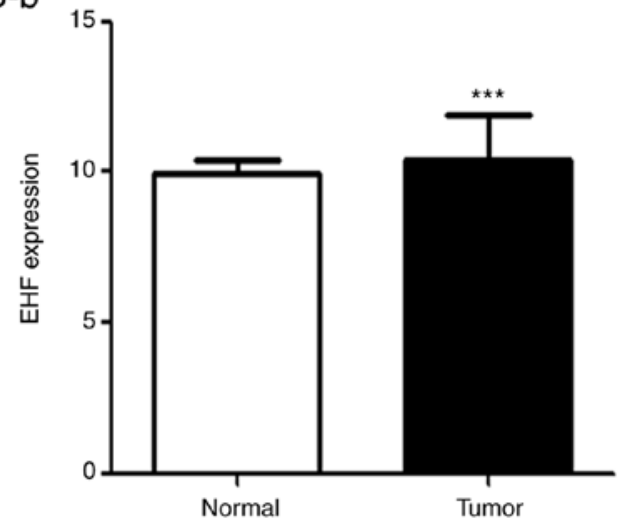

C

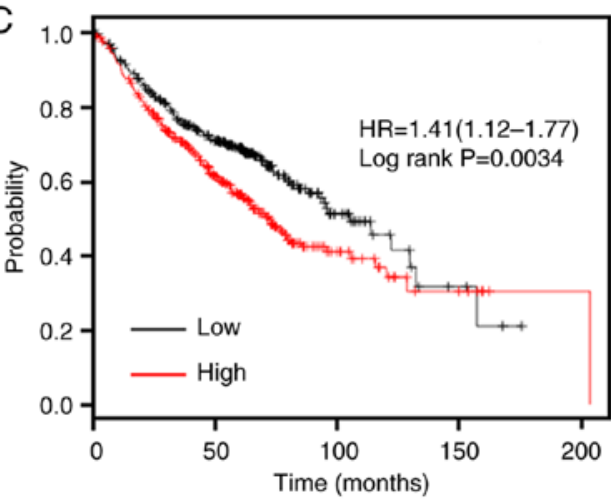

Number at risk

$\begin{array}{llllll}\text { Low } & 363 & 199 & 30 & 4 & 0 \\ \text { High } & 363 & 166 & 26 & 7 & 1\end{array}$

Figure 1. EHF expression is significantly higher in NSCLC tissues and is associated with a poor prognosis in patients with NSCLC. (A) EHF expression in 21 paired NSCLC tissues (T) and non-tumorous tissues (N) was assessed by real-time RT-qPCR and western blotting analyses, respectively. (B) EHF expression in lung adenocarcinoma (N=513, B-a) and squamous cancer (N=509, B-b) compared with normal tissues from the TCGA database cohort. (C) Kaplan-Meier survival curve analysis of patients with NSCLC stratified by EHF expression (data were plotted and calculated using the Kaplan-Meier plotter at http://kmplot. com/analysis/). ${ }^{*} \mathrm{P}<0.05$ and ${ }^{* * *} \mathrm{P}<0.001$. EHF, ETS-homologous factor; NSCLC, non-small cell lung cancer; RT-qPCR, reverse transcription-quantitative polymerase chain reaction; TCGA, The Cancer Genome Atlas.

secondary anti-mouse (cat. no. ASR1037) or anti-rabbit IgG (cat. no. ASR1089; both from Abcepta, Inc.) antibody at a dilution of $1: 15,000$ at $22^{\circ} \mathrm{C}$ and western blotting detection system (Immobilon ${ }^{\circledR}$ Western Chemiluminescent HRP Substrate; EMD Millipore). After exposure to chemiluminescence film, the same membrane was stripped in a stripping buffer containing $62.5 \mathrm{mM}$ Tris- $\mathrm{HCl}$ (pH6.8), $2 \%$ SDS and $0.8 \% \beta$-mercaptoethanol at $50^{\circ} \mathrm{C}$ for $45 \mathrm{~min}$, followed by washing 5 times. The membrane was then re-probed with anti-GAPDH antibody.

Statistical analysis. SPSS13.0 (SPSS, Inc.) was used for statistical analyses. Experiments were repeated 3 times, and the data were presented as the mean \pm standard deviation (SD). Student's t-tests were used for two group comparisons and AVOVA, followed by post hoc Tukey's test was used for multiple group comparisons. All statistical tests were two-sided. $\mathrm{P}<0.05$ or $\mathrm{P}<0.01$ indicated a statistically significant difference.

\section{Results}

Increased level of EHF expression in NSCLC is associated with poor prognosis. As revealed in Fig. 1A (left panel), the level of EHF transcript was 4-fold higher in NSCLC tissues compared to that in adjacent non-tumor tissues. Consistent 
A-a $A-b$
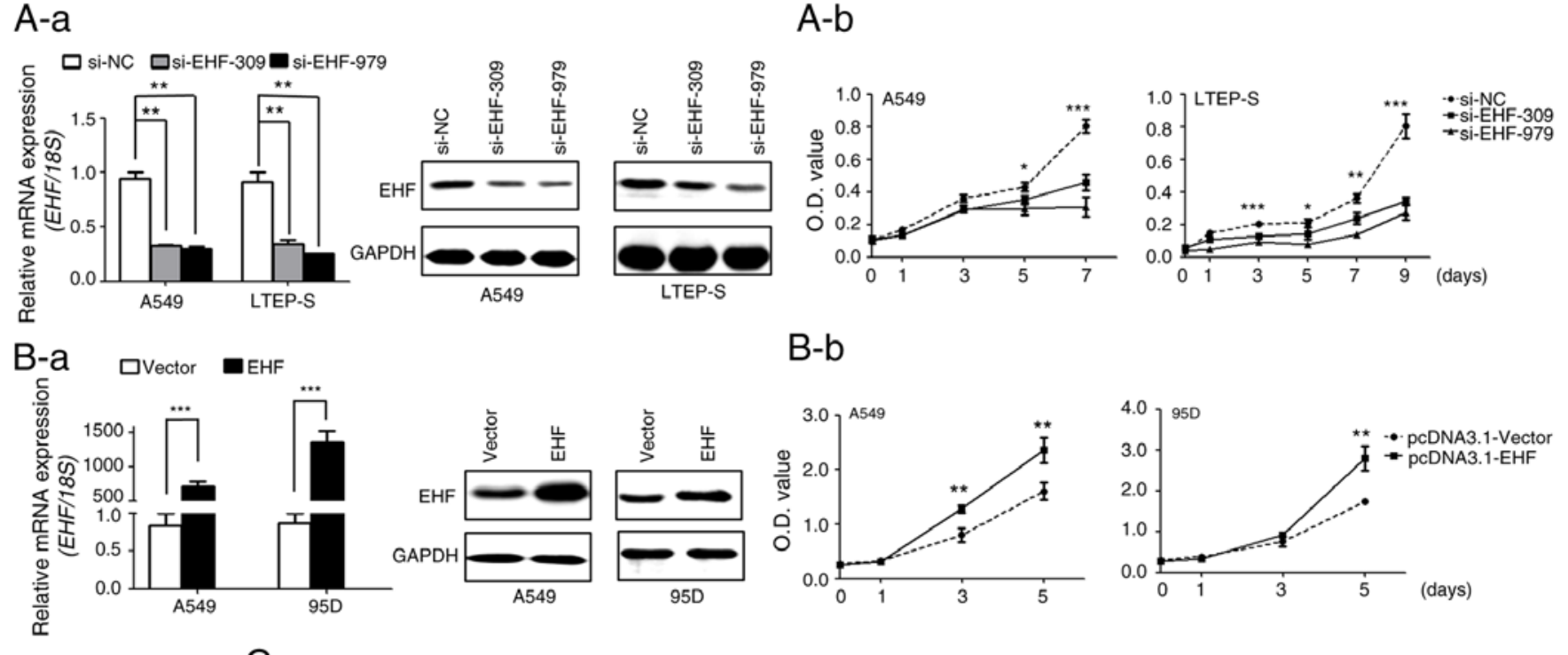

\section{B-b}
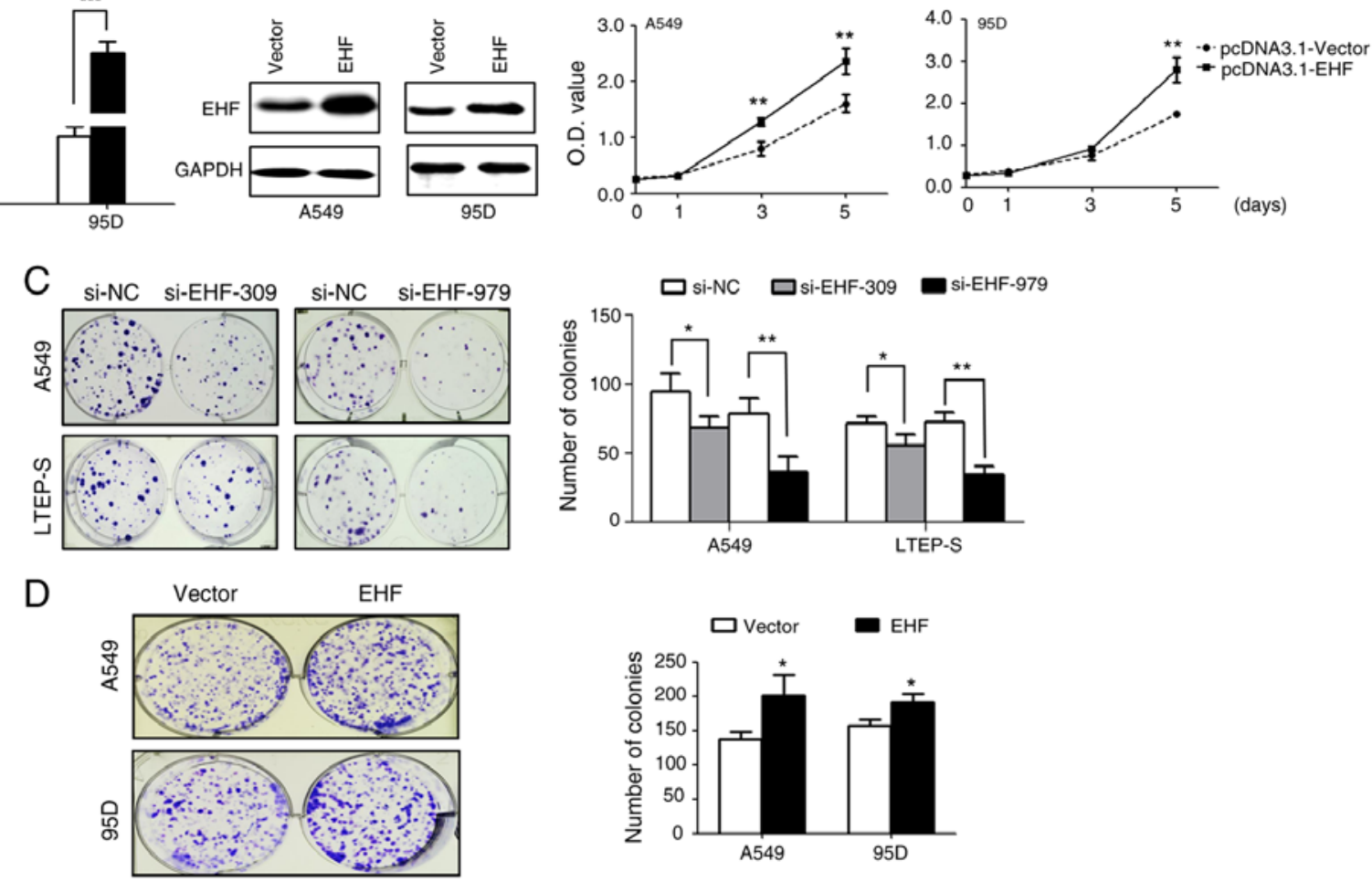

Figure 2. EHF promotes NSCLC cell proliferation and colony formation. (A-a) A549 and LTEP-s cells were transfected with siRNAs specific to EHF. EHF knockdown significantly inhibited (A-b) lung cancer cell proliferation and (C) colony formation. (B-b) A549 and 95D cells were transfected with pcDNA3.1(-) empty vector or pcDNA3.1-EHF. The overexpression of EHF significantly enhanced (B-b) cell proliferation and (D) colony formation. The data are presented as the mean $\pm \mathrm{SD} .{ }^{*} \mathrm{P}<0.05,{ }^{* *} \mathrm{P}<0.01$ and ${ }^{* * * *} \mathrm{P}<0.001$. EHF, ETS-homologous factor; NSCLC, non-small cell lung cancer; siRNAs, small interfering RNAs; SD, standard deviation; $\mathrm{NC}$, negative control.

with the real-time RT-qPCR data, the western blot analyses also detected increased levels of EHF expression in 3 tumors as compared to the corresponding control tissues (Fig. 1A, right panel). The data obtained from TCGA database was also analyzed and it was revealed that EHF was significantly higher in patients with lung adenocarcinoma and squamous cancer as compared to the corresponding controls (Fig. 1B). Notably, a Kaplan-Meier plot exhibited an association of the median of EHF expression level with the overall survival. An increased level of EHF expression was significantly associated with poor prognosis in patients with lung cancer at early stages (Fig. 1C).

Overexpression of EHF promotes lung cancer cell proliferation, tumor growth, cell migration and invasion. To study the role of EHF overexpression in lung cancer growth, EHF expression we first knocked down in cancer cells with siRNA. As revealed in Fig. 2A-a, transfection of cancer cells with siRNAs against different regions of EHF mRNA, knocked down EHF expression at both transcript and protein levels by
$60-70 \%$ in lung cancer cell lines. In addition, knockdown of EHF expression significantly diminished cancer cell proliferation (Fig. 2A-b). In contrast, overexpression of EHF increased lung cancer cell proliferation by 50\% in both cell lines (Fig. 2B-a and B-b). In agreement with the cell proliferation data, it was revealed that downregulation of EHF expression also caused a $20-50 \%$ reduction in cell colony formation whereas overexpression of EHF resulted in an increase in colony formation (Fig. 2C and D).

The effects of EHF expression on lung cancer cell migration and invasion were next evaluated. It was observed that the cells transfected with siRNA against EHF migrated and invaded markedly less than the control cells transfected with scramble siRNA (Fig. 3A and B). Knockdown of EHF expression in lung cancer cells caused a $30-50 \%$ reduction in cell migration and invasion. In contrast, overexpression of EHF in lung cancer cells increased cell migration and invasion by $30-40 \%$ as compared to corresponding controls (Fig. 3C and D). 
A
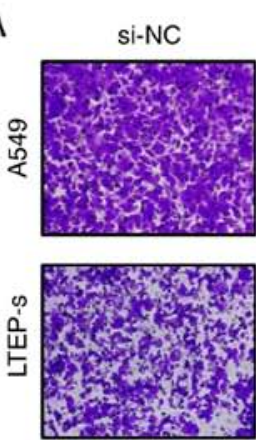

B
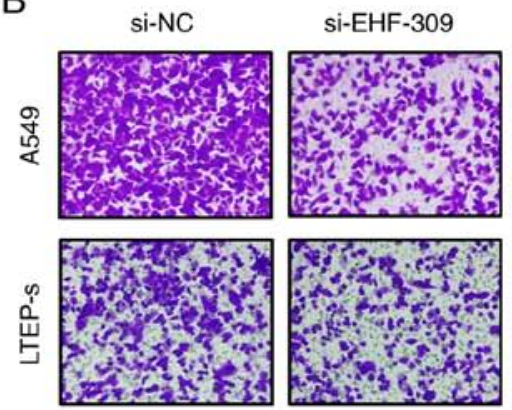

C
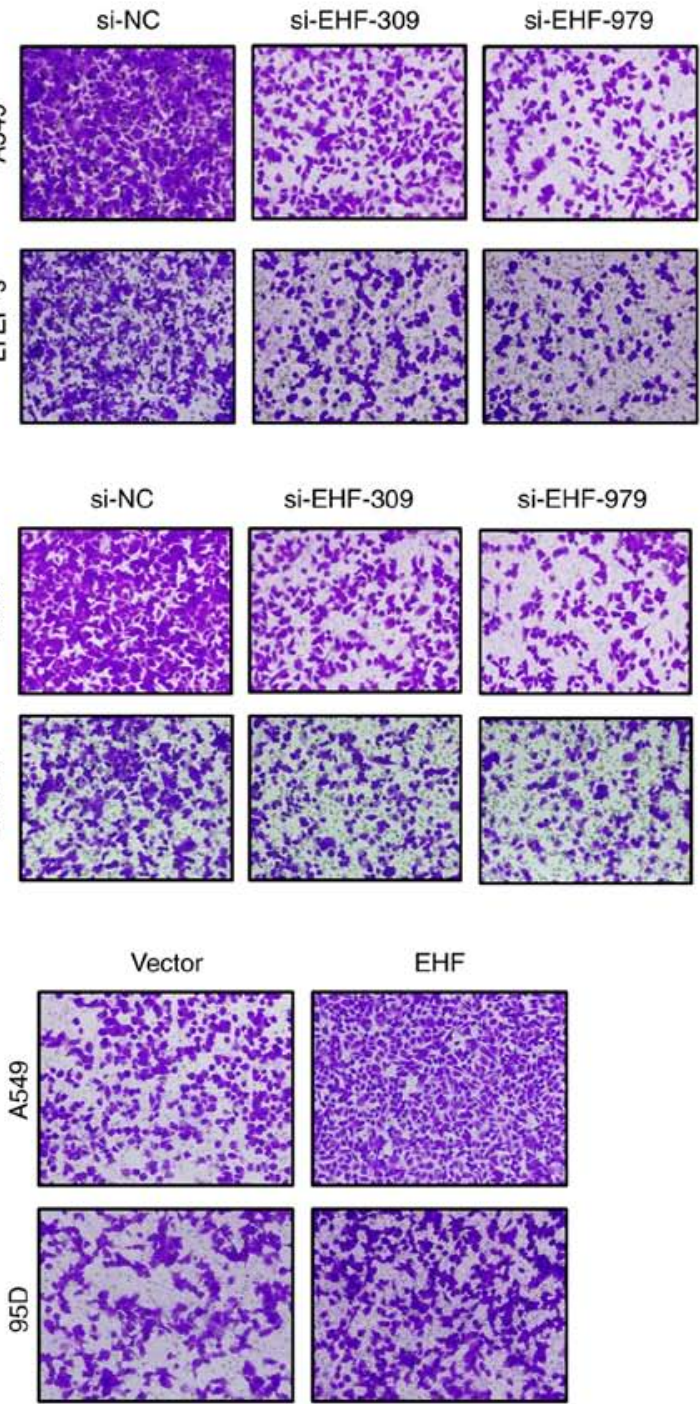

si-EHF-979
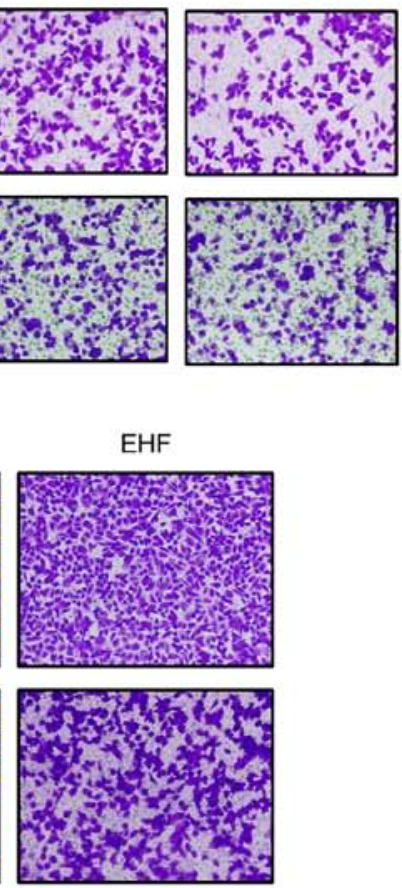

D
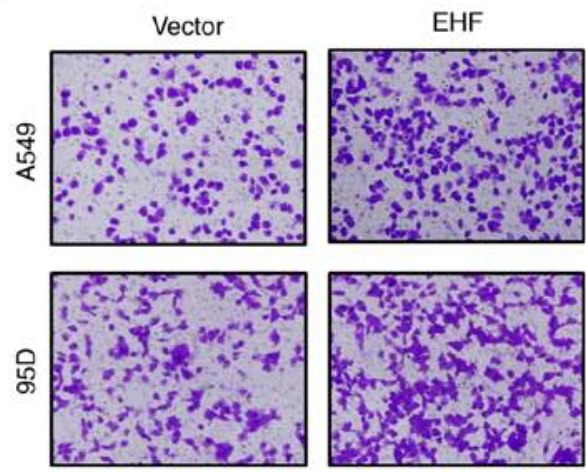
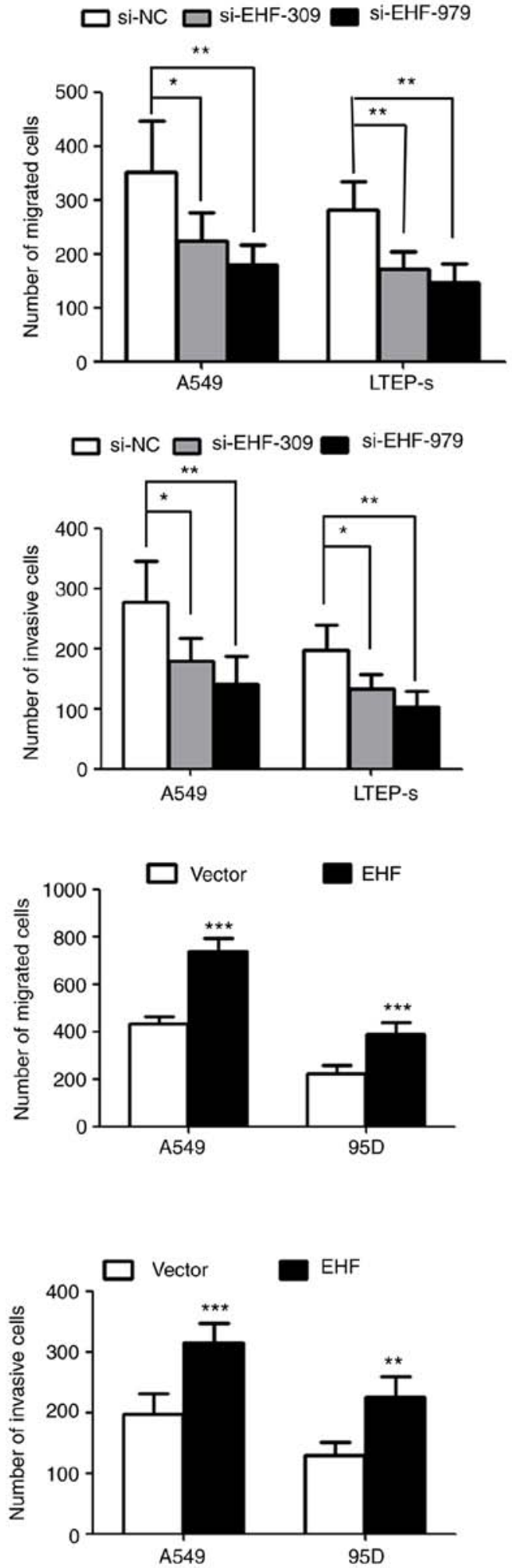

Figure 3. Knockdown of EHF expression inhibits NSCLC cell migration and invasion. The migration and invasion of lung cancer cells was determined using Millicell ${ }^{\circledR}$ cell culture inserts. The number of cells that migrated and invaded through the Matrigel ${ }^{\circledR}$ was counted in five fields under a $20 \mathrm{X}$ objective lens. (A) Knockdown of EHF expression on NSCLC cell migration. (B) Knockdown of EHF expression on NSCLC cell invasion. (C) Overexpression of EHF expression on NSCLC cell migration. (D) Overexpression of EHF on NSCLC cell invasion. The data are presented as the mean $\pm \mathrm{SD}$. ${ }^{*}<<0.05,{ }^{* *} \mathrm{P}<0.01$ and ${ }^{* * *} \mathrm{P}<0.001$. EHF, ETS-homologous factor; NSCLC, non-small cell lung cancer; si-, small interfering; SD, standard deviation; NC, negative control.

EHF downregulation arrests NSCLC cell cycle and induces NSCLC cell apoptosis. To study whether EHF downregulation arrests the cell cycle, growth inhibition of NSCLC cells transfected with si-EHF-979 or control siRNA was determined by flow cytometric analyses. As revealed in Fig. 4A, knockdown of EHF expression by si-EHF-797 arrested NSCLC cells at the $G_{0} / G_{1}$ phase. The percentage of cells in the $G_{0} / G_{1}$ phase was increased by $12 \%$ in A549 cells transfected with siEHF-979 as compared with cells transfected with control scramble siRNA $(54.85 \pm 4.01$ vs. $42.61 \pm 2.19 \%, \mathrm{P}=0.026)$, 

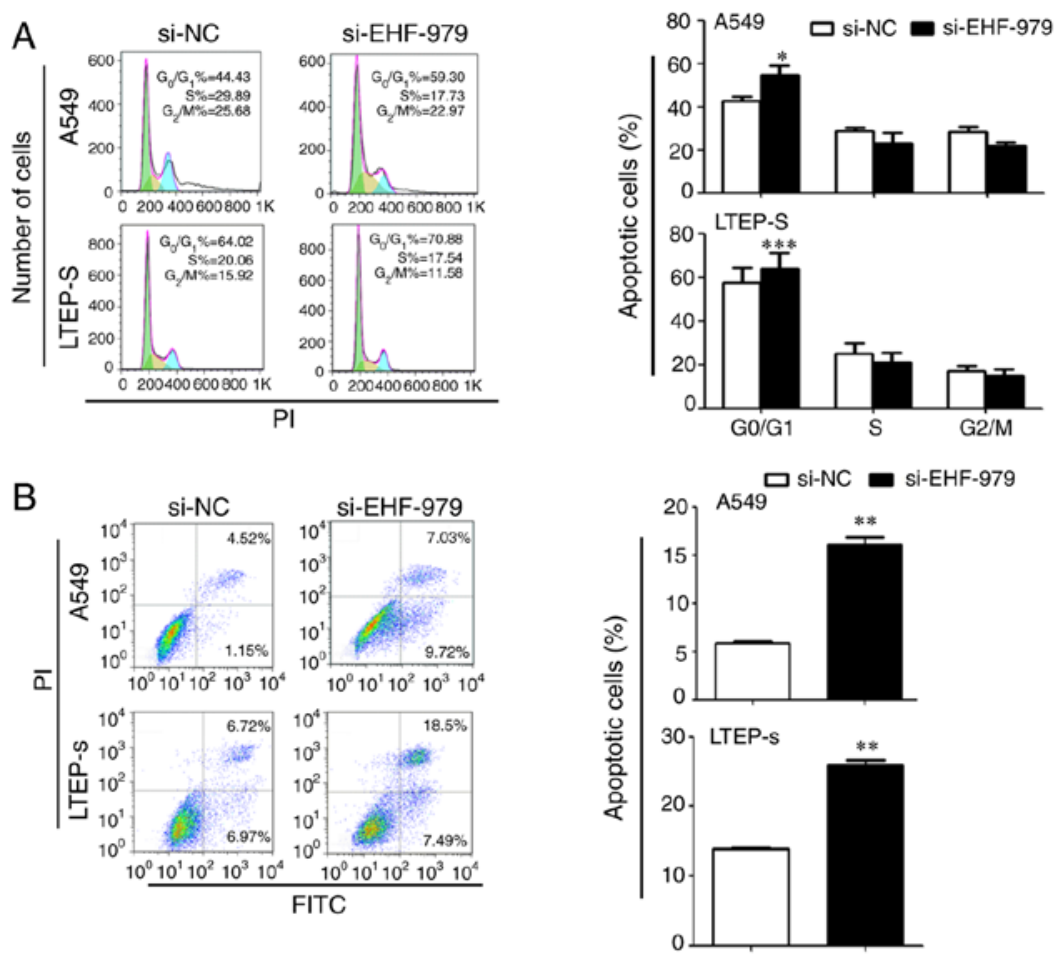

\section{C-a}

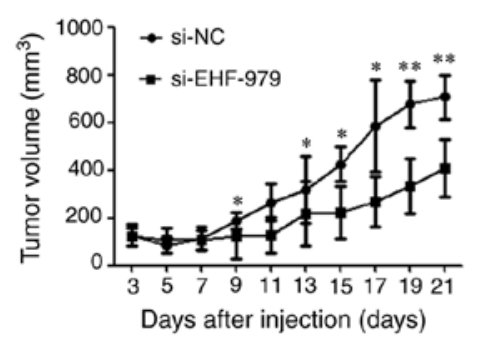

C-b

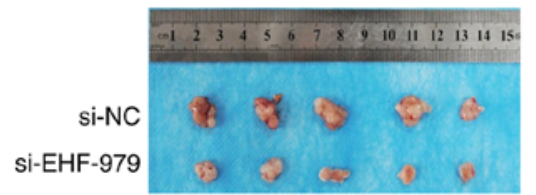

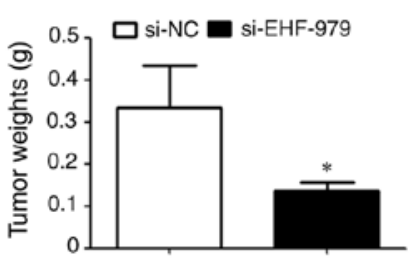

C-C
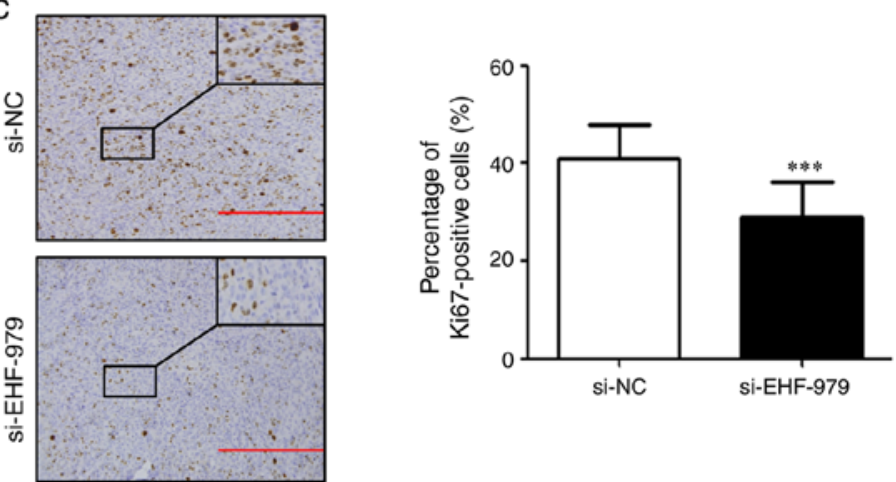

Figure 4. EHF knockdown induces cell cycle arrest and apoptosis in NSCLC cells. (A) Cells were transfected with NC siRNA or siRNA against EHF for $72 \mathrm{~h}$. The cell cycle distribution of each culture was determined by flow cytometry. (B) Cells treated as described in A were subjected to apoptosis analyses using Annexin V/propidium iodide staining. (C) Knockdown of EHF in NSCLC cells impairs tumor growth in vivo. Ten mice were randomly divided into two groups $(\mathrm{N}=5)$. (C-a) Tumors were excised 21 days after the injection of NSCLC cells. The average volume of tumors derived from the indicated cells was measured every 2 days after injection. (C-b) The average weight of tumors derived from the indicated cells in each group was assessed. (C-c) The expression of Ki67 in tissues was determined by immunohistochemistry. Representative images of knockdown tissues with weak and strong expression of Ki67 are presented. The data are presented as the mean \pm SD. ${ }^{*} \mathrm{P}<0.05,{ }^{* *} \mathrm{P}<0.01$ and ${ }^{* * * *} \mathrm{P}<0.001$. EHF, ETS-homologous factor; NSCLC, non-small cell lung cancer; si-, small interfering; SD, standard deviation; NC, negative control.

and $16 \%$ in LTEP-s cells transfected with siEHF-979 (73.95 \pm 6.97 vs. $57.59 \pm 7.75 \%, \mathrm{P}<0.001)$. It was also investigated whether EHF downregulation induced NSCLC cell apoptosis. As revealed in Fig. 4B, knockdown of EHF expression by siRNA resulted in an $11 \%$ increase in apoptotic A549 cells $(16.03 \pm 0.89$ vs. $5.89 \pm 0.23 \%, \mathrm{P}=0.003)$ and a $12 \%$ increase in apoptotic LTEP-s cells $(25.89 \pm 0.77$ vs. $13.88 \pm 0.17 \%, \mathrm{P}=0.002)$.
EHF downregulation suppresses tumor growth in A549 cell xenograftedmice. To evaluate the effect of EHF downregulation on tumor growth in vivo, xenografted mice bearing A549 lung cancer cells were generated. Consistent with the in vitro experiments, knockdown of EHF expression significantly decreased xenografted tumor growth in vivo (Fig. $4 \mathrm{C}-\mathrm{a}$ and C-b). The volume of xenografted tumors derived from si-EHF-979 A549 
A
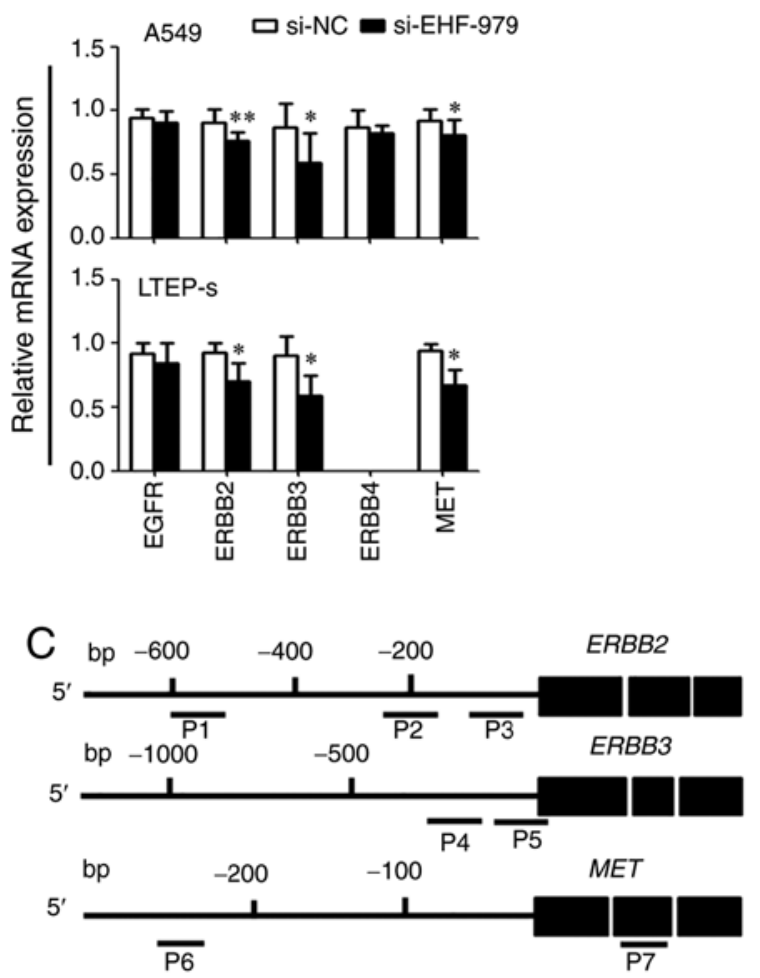
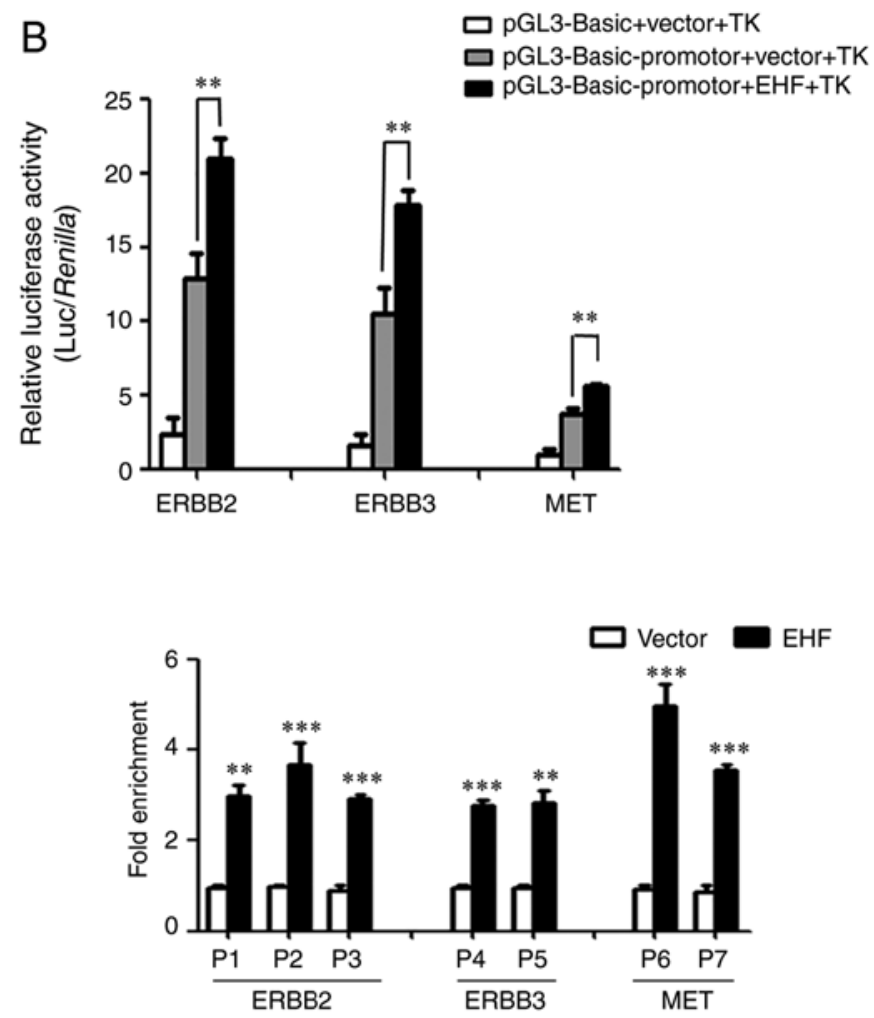

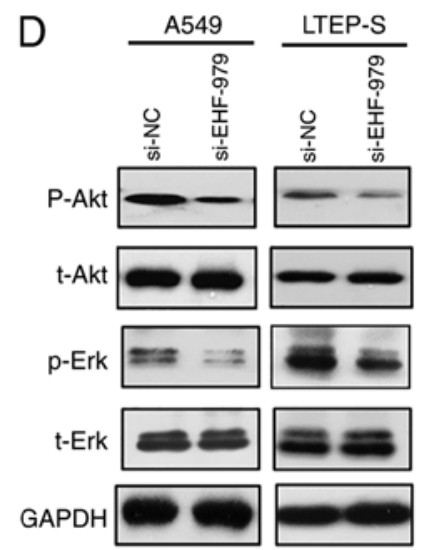

Figure 5. EHF regulates the expression of ERBB2, ERBB3 and MET in NSCLC cells via binding to EHF response elements in the promoter regions. (A) EHF knockdown reduced the expression of ERBB family members and MET, as assessed by real-time RT-qPCR. Data are presented as the mean \pm SD. (B) EHF regulated promoter activities of ERBB2, ERBB3 and MET by binding to EHF response elements, as determined by luciferase assays. Proximal promoter regions of ERBB2 (-607/+11), ERBB3 (-997/+440) and MET (-223/+60) were inserted into the pGL3-basic plasmid to generate luciferase reporters pGL3-ERBB2-Luc, pGL3-ERBB3-Luc, and pGL3-MET-Luc. 95D cells were co-transfected with reporters indicated with either pcDNA3.1/Myc-His (-) A-EHF or empty control vector. pRL-TK reporter was co-transfected as an internal control to normalize the transfection efficiency. Fold-enrichment data are presented as the mean \pm SD of three independent assays. (C) EHF binds to EHF response elements in the proximal promoter regions of ERBB2, ERBB3, and MET, as determined by ChIP analyses. P1-P7 represent the regions analyzed by ChIP assays for ERBB2, ERBB3 and MET. 95D cells were transiently transfected with pcDNA3.1/Myc-His (-) A-EHF or empty control vector and were subjected to ChIP-qPCR assays using an anti-Myc tag antibody. ChIP-PCR products arere presented in right panel. (D) EHF knockdown reduced phosphorylation of AKT and ERK in NSCLC cells, as assessed by western blot analyses. GAPDH was used as a loading control. ${ }^{*} \mathrm{P}<0.05,{ }^{* *} \mathrm{P}<0.01$ and ${ }^{* * *} \mathrm{P}<0.001$. ERBB2, Erb-B2 receptor tyrosinekinase 2; ERBB3, Erb-B2 receptor tyrosine kinase 3; ERBB4, Erb-B2 receptor tyrosine kinase 4; MET, mesenchymal-epithelial transition factor; EHF, ETS-homologous factor; NSCLC, non-small cell lung cancer; RT-qPCR, reverse transcription-quantitative polymerase chain reaction; SD, standard deviation; ChIP, chromatin immunoprecipitation; si-, small interfering; NC, negative control.

cells at day 21 was reduced by $38 \%$ as compared to the control xenografts $(\mathrm{P}<0.05)$. To quantify the proliferation index in the xenograft tumors, immunohistochemistry was performed. The tumor sections were probed with an antibody specific to Ki67 or control IgG. As revealed in Fig. 4C-c, knockdown of EHF expression by siRNA (si-EHF-979) significantly decreased the population of Ki67-positive cells in tumors as compared with the tumors transfected with control siRNA (si-NC). The percentage of Ki67-positive cells was reduced by $25 \%$ in si-EHF-979 transfected tumors $(\mathrm{P}<0.001)$.

EHF promotes tumor growth by regulating ERBB2, ERBB3 and MET expression and activating the AKT/ERK signaling pathways in NSCLC cells. To study the mechanism of EHF 
regulation of tumor growth, the expression of potential EHF target genes in EHF knocked down NSCLC cells in vitro was first examined. As revealed in Fig. 5A, the expression levels of ERBB2, ERBB3, and MET were reduced by 20-30\% in both EHF knocked down cell lines compared with the controls. It was revealed that ERBB4 expression was very low in LTEP-s cells and undetectable by qPCR. No changes in the levels of EGFR and ERBB4 expression were detectable in A549 cells or in LTEP-s cells (Fig. 5A). To further study the regulation of EHF on the promoter activity of EHF target genes, proximal promoters of ERBB2, ERBB3 and MET genes were inserted into promoter-less pGL3-basic plasmid and luciferase reporter assays in co-transfected cancer cells were performed. The Renilla luciferase activity driven by TK minimal promoter in co-transfected cells was used as an internal control to normalize the transfection efficiency. The results revealed that overexpression of EHF in lung cancer cells enhanced luciferase reporter activity by $40 \%$ in the cells co-transfected with EHF expression plasmid and the luciferase reporters driven by ERBB2, ERBB3 and MET proximal promoters, respectively, as compared to the control cells co-transfected with corresponding reporters with a control plasmid (Fig. 5B). In addition, the promoter activities were also increased in the lung cancer cells transfected with luciferase reporters under the control of ERBB2, ERBB3 and MET proximal promoters as compared with the cells transfected with promoter-less reporter (Fig. 5B). To determine whether EHF regulates endogenous ERBB2, ERBB3 and MET expression in cancer cells, we carried out ChIP assays. As revealed in Fig. 5C, the ChIP assays detected EHF binding to the promoters of endogenous ERBB2, ERBB3 and MET genes, respectively. The interactions of EHF with ERBB2, ERBB3 and MET proximal promoters were increased by more than 2 -fold in the EHF-overexpressing cells as compared to the straight control cells.

It was next determined whether inhibition of tumor growth by knockdown of EHF expression with siRNA was mediated by modulating the EGF receptor-mediated AKT and ERK signaling pathways in lung cancer cells. As revealed in Fig. 5D, downregulation of EHF expression resulted in a reduction in AKT and ERK phosphorylation while total protein expression of AKT or ERK in the transfected cells was not altered.

\section{Discussion}

ETS transcription factors play crucial roles in several biological processes including cell proliferation, differentiation, organ development, and tumorigenesis by modulating the target gene expression via binding to their cis-elements of GGAA/T in the regulatory regions $(4,5,22)$. In the present study, we performed a computer-assisted EST library screening and determined that an epithelium-specific ETS factor, EHF/ESE-3 contained a putative DNA binding domain similar to a known consensus motif of ESE-1 that is known to bind to the promoter regions of EGFR family members (10). In agreement with our prediction, the ChIP and promoter/reporter assays revealed that EHF was able to bind to the promoters of ERBB2, ERBB3 and MET genes and regulate the promoter activities in NSCLC cells. Because EHF expression was increased in NSCLC tissue compared with adjacent non-tumor tissue and overexpression of EHF was associated with poor prognosis in patients with NSCLC, it was surmised that changes in EHF expression in cancers would alter tumor behaviors. As anticipated, knockdown of EHF expression in NSCLC cells with specific siRNA inhibited cell proliferation and invasion, arrested the cell cycle at the $G_{0} / G_{1}$ phase, and induced cancer cell apoptosis whereas overexpression of EHF in NSCLC cells promoted cell proliferation as well as tumor growth and migration in vitro. The in vivo experiments also confirmed that knockdown of EHF expression in NSCLC cells significantly inhibited cancer progression in xenografted nude mice as compared to control mice grafted with NSCLC cells transfected with control siRNA. It was demonstrated that EHF overexpression in NSCLC cells could stimulate the expression of ERBB2, ERBB3 and MET tyrosine kinase receptors and as such activate the AKT and ERK downstream signaling pathways to promote tumor growth. The present study indicated that EHF overexpression could be used as a prognostic marker for NSCLC, and tyrosine kinase receptors of ERBB2, ERBB3 and MET could be new drug targets for treatment of patients with NSCLC.

The ERBB family consists of EGFR family members ERBB1(HER1), ERBB2 (HER2), ERBB3 (HER3), and ERBB4 (HER4) (23). It is well known that the increased expression of EGFR family members are associated with the poor overall survival of patients with NSCLC (16). ERBB receptor activation initiates tyrosine kinase receptor signaling and activates downstream multiple signal cascades such as RAS/MAPK, $\mathrm{PI} 3 \mathrm{~K} / \mathrm{AKT}$, and signal transducer and activator of transcription (STAT), thus regulating tumor growth, survival, and angiogenesis $(24,25)$. While MET is another heterodimeric transmembrane receptor tyrosine kinase (26) composed of an extracellular $\alpha$-chain and a transmembrane-spanning $\beta$-chain linked via disulfide bonds, activation of the tyrosine kinase domain also mediates downstream PI3K/AKT, MAPK, and phospholipase $\mathrm{C}$ signaling pathways. Mutations of MET in patients with cancers have been suggested to contribute to oncogenic progression (27-30). A recent study has demonstrated that approximately $40 \%$ of patients with small-cell lung cancer or NSCLC carry the tumor cells in which MET receptor is overexpressed (17). These studies raised a question as whether there is crosstalk between MET and ERBB2 or ERBB3 family members that contributes to cancer cell resistance to RTK-targeted inhibitors (31). If there is, then inhibition of EGFR or MET signaling alone may result in a functional compensation of other signaling. In supporting this assumption, previous studies revealed that the amplification of the MET gene caused gefitinib resistance due to activation of ERBB3-dependent PI3K signaling (32), a pathway specific to EGFR/ERBB family receptors activated via switching to an alternative bypass survival signaling (33). In the present study, it was demonstrated that expression levels of ERBB2/3 and MET were regulated by EHF; inhibition of one signaling of EHF target genes would not inactivate others. It is possible that suppression of one signaling pathway would activate others by a feedback mechanism. While we do not have direct evidence suggesting that the interaction of ERBB2/3 with MET would result in a synergized function on cancer cell migration and/or invasion, it is theorized they may crosstalk and have additional 
or synergized cellular functions. Further studies are required to confirm this theory. Nevertheless, the present findings provide experimental evidence that there may be crosstalk between MET and EGFR and a combination of MET and EGFR inhibitors is required to sufficiently block downstream EGFR/RTK signaling pathways for NSCLC treatment (34).

$\mathrm{EHF} / \mathrm{ESE} 3$ is located at $11 \mathrm{p} 12$ which is a hotspot for loss of heterozygosity in lung, breast, and prostate carcinomas (11). In contrast to our findings in lung cancers, a previous study revealed that the loss of EHF expression in prostate epithelial cells due to DNA methylation and gene silencing resulted in epithelial-mesenchymal transition, tumor-initiation, and cancer cell metastasis (14). Re-expression of EHF in prostate cancer cells induced cancer cell apoptosis (35). A previous study also revealed that knockdown of EHF expression in ovarian cancer cells stimulated the expression of cyclin B1, cyclin D1, and PCNA, causing an increase in cell proliferation and cancer progression (36). In airway epithelial cells including A549 and Calu-3 cell lines, EHF-regulated protein expression was involved in intercellular and cell-matrix adhesion in response to wound healing (37). The significant difference of EHF functions in different cells or tissues suggests that EHF could be a tissue-specific repressor or enhancer, and its function in cancer cells may depend on interaction with other transcription factor/co-activators/co-repressors on the promoter region of EHF target genes and chromatin remodeling. Further studies are required to determine how EHF interacts with other regulatory factors and remodels chromatin architectures to induce EGFR and MET expression in NSCLC as well as in prostate cancer cells.

In conclusion, the role of EHF in NSCLC progression in vitro and in vivo was investigated and it was demonstrated that EHF expression was increased in NSCLC. Knockdown of EHF expression with specific siRNA in NSCLC cells significantly inhibited cell proliferation and invasion, arrested the cell cycle at the $G_{0} / G_{1}$ phase, and induced apoptosis whereas overexpression of EHF in NSCLC cells promoted cell proliferation, tumor growth, and cancer cell migration in vitro. Knockdown of EHF expression in NSCLC cells also suppressed tumor growth in xenografted nude mice. It was also demonstrated that EHF promoted NSCLC growth by directly regulating transcripts of ERBB2, ERBB3 and MET tyrosine kinase receptors and modulating AKT and ERK signals via binding to the promoter of EHF target genes. The present findings indicated that EHF could be used as a prognostic marker for NSCLC, and tyrosine kinase receptors of ERBB2, ERBB3 and MET could be new drug targets for NSCLC treatment.

\section{Acknowledgements}

Not applicable.

\section{Funding}

Not applicable.

\section{Availability of data and materials}

All data generated or analyzed during this study are included in this published article.

\section{Authors' contributions}

LG and MC conceived and supervised the study. LG, TY and MC designed the experiments. LG, TY, SZ and YL performed experiments. TY, YL, PS and HR contributed to the collection and analysis of data. LG and $\mathrm{PH}$ drafted the manuscript. PH and MC made manuscript revisions. All authors have read the final version and have approved the submission of this study.

\section{Ethics approval and consent to participate}

The study was approved by the Institutional Review Board and Human Ethics Committee of the First Affiliated Hospital of Xi'an Jiaotong University, and written informed consent was obtained from each patient. The animal experiments were approved by the Institutional Animal Care and Use Committee of Xi'an Jiaotong University.

\section{Patient consent for publication}

Not applicable.

\section{Competing interests}

The authors declare that they have no competing interests.

\section{References}

1. Torre LA, Bray F, Siegel RL, Ferlay J, Lortet-Tieulent J and Jemal A: Global cancer statistics, 2012. CA Cancer J Clin 65: 87-108, 2015

2. Devesa SS, Bray F, Vizcaino AP and Parkin DM: International lung cancer trends by histologic type: Male:Female differences diminishing and adenocarcinoma rates rising. Int J Cancer 117: 294-299, 2005.

3. Jemal A, Bray F, Center MM, Ferlay J, Ward E and Forman D: Global cancer statistics. CA Cancer J Clin 61: 69-90, 2011.

4. Sementchenko VI and Watson DK: Ets target genes: Past, present and future. Oncogene 19: 6533-6548, 2000.

5. Seth A and Watson DK: ETS transcription factors and their emerging roles in human cancer. Eur J Cancer 41: 2462-2478, 2005.

6. Wasylyk B, Hagman J and Gutierrez-Hartmann A: Ets transcription factors: Nuclear effectors of the Ras-MAP-kinase signaling pathway. Trends Biochem Sci 23: 213-216, 1998.

7. Trojanowska M: Ets factors and regulation of the extracellular matrix. Oncogene 19: 6464-6471, 2000

8. Benz CC, O'Hagan RC, Richter B, Scott GK, Chang CH, Xiong X, Chew K, Ljung BM, Edgerton S, Thor A and Hassell JA: HER2/Neu and the Ets transcription activator PEA3 are coordinately upregulated in human breast cancer. Oncogene 15: 1513-1525, 1997.

9. Eckel KL, Tentler JJ, Cappetta GJ, Diamond SE and Gutierrez-Hartmann A: The epithelial-specific ETS transcription factor ESX/ESE-1/Elf-3 modulates breast cancer-associated gene expression. DNA Cell Biol 22: 79-94, 2003.

10. Kas K, Finger E, Grall F, Gu X, Akbarali Y, Boltax J, Weiss A, Oettgen P, Kapeller R and Libermann TA: ESE-3, a novel member of an epithelium-specific ets transcription factor subfamily, demonstrates different target gene specificity from ESE-1. J Biol Chem 275: 2986-2998, 2000

11. Kleinbaum LA, Duggan C, Ferreira E, Coffey GP, Buttice G and Burton FH: Human chromosomal localization, tissue/tumor expression, and regulatory function of the ets family gene EHF. Biochem Biophys Res Commun 264: 119-126, 1999.

12. Cangemi R, Mensah A, Albertini V, Jain A, Mello-Grand M, Chiorino G, Catapano CV and Carbone GM: Reduced expression and tumor suppressor function of the ETS transcription factor ESE-3 in prostate cancer. Oncogene 27: 2877-2885, 2008. 
13. Shaikhibrahim Z, Lindstrot A, Langer B, Buettner R and Wernert N: Differential expression of ETS family members in prostate cancer tissues and androgen-sensitive and insensitive prostate cancer cell lines. Int J Mol Med 28: 89-93, 2011.

14. Turcotte S, Forget MA, Beauseigle D, Nassif E and Lapointe R: Prostate-derived Ets transcription factor overexpression is associated with nodal metastasis and hormone receptor positivity in invasive breast cancer. Neoplasia 9: 788-796, 2007.

15. Brenne K, Nymoen DA, Hetland TE, Trope CG and Davidson B Expression of the Ets transcription factor EHF in serous ovarian carcinoma effusions is a marker of poor survival. Hum Pathol 43 : 496-505, 2012

16. Hynes NE and MacDonald G: ErbB receptors and signaling pathways in cancer. Curr Opin Cell Biol 21: 177-184, 2009.

17. Gelsomino F, Facchinetti F, Haspinger ER, Garassino MC, Trusolino L, De Braud F and Tiseo M: Targeting the MET gene for the treatment of non-small-cell lung cancer. Crit Rev Oncol Hematol 89: 284-299, 2014.

18. Zhang S, Gao L, Thakur A, Shi P, Liu F, Feng J, Wang T, Liang Y, Liu JJ, Chen M and Ren H: MiRNA-204 suppresses human non-small cell lung cancer by targeting ATF2. Tumour Biol 37: 11177-11186, 2016.

19. Livak KJ and Schmittgen TD: Analysis of relative gene expression data using real-time quantitative PCR and the 2(-Delta Delta C(T)) method. Methods 25: 402-408, 2001.

20. Wang P, Henning SM and Heber D: Limitations of MTT and MTS-based assays for measurement of antiproliferative activity of green tea polyphenols. PLoS One 5: e10202, 2010.

21. Shi J, Liu W, Sui F, Lu R, He Q, Yang Q, Lv H, Shi B and Hou P. Frequent amplification of AIB1, a critical oncogene modulating major signaling pathways, is associated with poor survival in gastric cancer. Oncotarget 6: 14344-14359, 2015.

22. Hollenhorst PC, Jones DA and Graves BJ: Expression profiles frame the promoter specificity dilemma of the ETS family of transcription factors. Nucleic Acids Res 32: 5693-5702, 2004.

23. Roskoski R Jr: The ErbB/HER family of protein-tyrosine kinases and cancer. Pharmacol Res 79: 34-74, 2014.

24. Holbro T, Civenni G and Hynes NE: The ErbB receptors and their role in cancer progression. Exp Cell Res 284: 99-110, 2003.

25. Roskoski R Jr: The ErbB/HER receptor protein-tyrosine kinases and cancer. Biochem Biophys Res Commun 319: 1-11, 2004.

26. Petrini I: Biology of MET: A double life between normal tissue repair and tumor progression. Ann Transl Med 3: 82, 2015.
27. Cappuzzo F, Marchetti A, Skokan M, Rossi E, Gajapathy S, Felicioni L, Del Grammastro M, Sciarrotta MG, Buttitta F, Incarbone M, et al: Increased MET gene copy number negatively affects survival of surgically resected non-small-cell lung cancer patients. J Clin Oncol 27: 1667-1674, 2009.

28. Fu P, Du F, Yao M, Lv K and Liu Y: MicroRNA-185 inhibits proliferation by targeting c-Met in human breast cancer cells. Exp Ther Med 8: 1879-1883, 2014.

29. Hagman Z, Haflidadottir BS, Ansari M, Persson M, Bjartell A, Edsjö A and Ceder Y: The tumour suppressor miR-34c targets MET in prostate cancer cells. Br J Cancer 109: 1271-1278, 2013.

30. Phan LM, Fuentes-Mattei E, Wu W, Velazquez-Torres G, Sircar K, Wood CG, Hai T, Jimenez C, Cote GJ, Ozsari L, et al: Hepatocyte Growth Factor/cMET pathway activation enhances cancer hallmarks in adrenocortical carcinoma. Cancer Res 75: 4131-4142, 2015.

31. Maroun CR and Rowlands T: The Met receptor tyrosine kinase: A key player in oncogenesis and drug resistance. Pharmacol Ther 142: 316-338, 2014.

32. Engelman JA, Zejnullahu K, Mitsudomi T, Song Y, Hyland C, Park JO, Lindeman N, Gale CM, Zhao X, Christensen J, et al: MET amplification leads to gefitinib resistance in lung cancer by activating ERBB3 signaling. Science 316: 1039-1043, 2007.

33. Karamouzis MV, Konstantinopoulos PA and Papavassiliou AG Targeting MET as a strategy to overcome crosstalk-related resistance to EGFR inhibitors. Lancet Oncol 10: 709-717, 2009.

34. Troiani T, Martinelli E, Napolitano S, Vitagliano D, Ciuffreda LP, Costantino S, Morgillo F, Capasso A, Sforza V, Nappi A, et al: Increased TGF- $\alpha$ as a mechanism of acquired resistance to the anti-EGFR inhibitor cetuximab through EGFR-MET interaction and activation of MET signaling in colon cancer cells. Clin Cancer Res 19: 6751-6765, 2013.

35. Luk IY, Reehorst CM and Mariadason JM: ELF3, ELF5, EHF and SPDEF transcription factors in tissue homeostasis and cancer. Molecules 23: 2191, 2018.

36. Cheng Z, Guo J, Chen L, Luo N, Yang W and Qu X: Knockdown of EHF inhibited the proliferation, invasion and tumorigenesis of ovarian cancer cells. Mol Carcinog 55: 1048-1059, 2016.

37. Fossum SL, Mutolo MJ, Yang R, Dang H, O'Neal WK, Knowles MR, Leir SH and Harris A: Ets homologous factor regulates pathways controlling response to injury in airway epithelial cells. Nucleic Acids Res 42: 13588-13598, 2014.

(1) $\Theta$ This work is licensed under a Creative Commons

Attribution-NonCommercial-NoDerivatives 4.0 International (CC BY-NC-ND 4.0) License. 